\title{
Produção de Situações-problema em curso de extensão universitária por professores de Ciências da Natureza dos anos finais e ensino médio da rede básica de ensino
}

\author{
Production of problem situations in the course of university extension by teachers of Natural \\ Sciences of the final years and high school of the basic education network
}

\author{
Vanessa Fagundes Siqueira ${ }^{1}$ \\ Mara Elisângela Jappe Goi ${ }^{2}$ \\ Jaqueline Pinto Vargas ${ }^{3}$ \\ Ricardo Machado Ellensohn ${ }^{4}$
}

\section{RESUMO}

Neste trabalho serão apresentados e discutidos os dados extraídos de um curso de formação continuada de professores da área de Ciências da Natureza realizado na Universidade Federal do Pampa (Unipampa), campus Caçapava do Sul, Rio Grande do Sul. A experiência realizada indica o desenvolvimento de competências no processo de elaboração e resolução de problemas que pode ser realizado em curso de imersão com professores das áreas de Ciências da Natureza e essa se vincula à constituição de um grupo de formação continuada de professores, bem como se justifica pela necessidade de instituir um grupo docente embasado no estudo da Resolução de Problemas no Ensino de Ciências. Os resultados apontam que o trabalho desenvolvido oportunizou o aprimoramento de habilidades nos docentes, bem como contribuiu para minimizar as dificuldades encontradas na prática docente.

Palavras-chave: Resolução de Problemas. Formação de professores. Ensino de Ciências.

\begin{abstract}
This paper will present and discuss the data extracted from a course of continuing education of teachers of the area of Natural Sciences, held at the Federal University of PampaUnipampa of the campus of Caçapava do Sul, State of Rio Grande do Sul, Brazil. The experience indicates the development of skills in the process of elaboration and problem solving that can be carried out in the course of immersion with teachers of the Natural Sciences areas and this is linked to the formation of a group of continuing teacher training, as well as justifies the need to establish a teaching group based on the study of Problem Solving in Science Teaching. The results show that the work developed facilitated the improvement of skills in teachers, as well as contributed to minimize the difficulties encountered in teaching practice.
\end{abstract}

Keywords: Solving problem. Teaching formation. Science teaching.

\footnotetext{
1 Graduanda em Ciências Exatas na Universidade Federal do Pampa, Rio Grande do Sul, Brasil (vanessaf21siqueira@gmail.com).

${ }^{2}$ Doutora em Educação pela Universidade Federal do Rio Grande do Sul, Brasil; professora da Universidade Federal do Pampa, Campus Caçapava do Sul, Rio Grande do Sul, Brasil (maragoi28@ gmail.com).

3 Doutora em Química pela Universidade Federal do Rio Grande do Sul, Brasil; professora adjunta na Universidade Federal do Pampa, campus Caçapava do Sul, Rio Grande do Sul, Brasil (jaquevgs@ gmail.com).

${ }^{4}$ Doutor em Síntese Orgânica (Organometálicos e Síntese Total) pela Universidade de São Paulo, Brasil, com estágios de pós-doutorado em Síntese Quiral (Compostos com atividade biológica) pela Universidade Estadual de Campinas, São Paulo, Brasil; professor adjunto e coordenador acadêmico na Universidade Federal do Pampa, campus Caçapava do Sul, Rio Grande do Sul, Brasil. (ricardoellensohn@ gmail.com).
} 


\section{INTRODUÇÃO}

Neste trabalho discute-se a análise de problemas produzidos pelos professores em um curso de formação continuada de professores da área de Ciências da Natureza, realizado na Universidade Federal do Pampa (Unipampa), campus Caçapava do Sul, Rio Grande do Sul.

O curso de extensão universitária aprofundou os aspectos epistemológicos de Larry Laudan (1977), pedagógicos de John Dewey (2010) e psicológicos de Jerome Bruner (1966) da RP (RP) para que cada professor em formação possa produzir seu próprio material didático e implementá-lo no contexto escolar.

Na perspectiva de que a ciência é, em essência, uma atividade de RP, trabalhou-se os referenciais de Laudan (1977), pelo fato do autor defender a tese de que a ciência deve ser ensinada a partir da atividade de RP e que nessas atividades devem estar imbricadas a história e a filosofia da ciência que deveriam compor os programas de educação científica de professores e o cotidiano das salas de aulas (GOI, 2014). Nessa perspectiva, Laudan (1977) considera que nem os filósofos, nem os historiadores da ciência têm dedicado tempo e atenção suficientes para a adequada compreensão do que é conceber a ciência como uma atividade de RP. Segundo o autor, a atividade de RP gera um progresso cognitivo, que se relaciona às aspirações intelectuais da ciência e assim ela progride pela maneira como resolve, adequadamente ou não, uma série de problemas gerados no meio social.

Quanto aos aspetos pedagógicos de RP tratados na formação de professores, foi aprofundado os referenciais de Dewey (2010) que apontam que os problemas devem ser produzidos a partir da experiência de cada indivíduo. Assim, uma escola com base na experiência de vida de cada estudante seria, na opinião de Dewey (2010,) um espaço que prioriza a individualidade de cada um, partindo da sua própria experiência, cujas características são variáveis em cada indivíduo.

Em relação aos aspectos psicológicos tratados na formação, foram aprofundados os referenciais de Bruner (2008), considerando que o autor entender que o indivíduo aprende resolvendo problemas e, consequentemente, recorre às pesquisas para resolver cada situação. Assim, o indivíduo que pesquisa, que encontra regularidades e relações na solução de um problema precisa estar com expectativa de que há algo para ser descoberto. Nesse sentido, o potencial intelectual, na visão do autor, deve ser marcado por transformar o que foi descrito em uma hipótese, bem como, enfatizar a descoberta levando a criança a aprender uma 
variedade de formas para resolver problemas e transformar a informação para uma melhor utilização.

Assim, essa formação foi organizada a partir de experiências já vivenciadas pelos professores formadores, em que foi possível elaborar um curso de aprofundamento teórico metodológico, considerando que os professores de Ciências da Natureza dos anos finais do Ensino Fundamental e do Ensino Médio não apresentam os conhecimentos necessários para a utilização da metodologia de RP em seus contextos escolares (GOI, 2014).

Ressalta-se que a equipe já trabalhou com este tema em cursos de aprofundamento, na modalidade de extensão, em disciplinas de graduação, especialização e mestrado, portanto, foi possível perceber que nessa modalidade há um tempo maior destinado para a elaboração dos problemas. Outra forma de se trabalhar com a RP, e essa parece eficaz, está relacionada aos professores em formação inicial produzirem seus Trabalhos de Conclusão de Curso (TCC) utilizando essa estratégia de ensino. Nesses trabalhos, o desenvolvimento das bases teóricas para a construção de problemas mais elaborados é mais evidente, e em geral, o trabalho se constitui como pesquisa (CARRER, 2008; BENTLIN, 2009; SANTOS, 2009; LEITE, 2009; BOLZAN, 2015; BOLZAN, 2015; PERES, 2015; FREITAS, 2015; SILVA, 2017).

Ressalta-se que, em todos os casos, quando são fornecidos aos professores em formação argumentos teóricos e metodológicos para o trabalho com RP, os mesmos sentem-se mais seguros para utilizar essa estratégia de ensino em suas salas de aula. Assim, considera-se relevante o investimento em formação inicial e continuada de professores e a necessidade de pensar e estruturar os cursos de formação continuada juntamente com os docentes que participarão dessas propostas, pois podem ser desenvolvidos na perspectiva da realidade, abordando os problemas vividos no contexto escolar e no município ao qual pertencem (SOUZA, 2007), posto que "perspectivar a formação de professores em um quadro paradigmático reflexivo, é criar as condições para que tal aconteça" (LEITÃO; ALARCÃO, 2006, p. 67). Assim, a formação continuada de professores "pode propiciar o desenvolvimento das potencialidades de cada um, o que requer o desenvolvimento de si próprio como pessoa" (ABREU, 2006, p. 23).

Libâneo e Pimenta (1999) enfocam na ideia de que a formação continuada pode ser realizada na universidade articulada à formação inicial, pois ao estimular cursos que unam os professores da Educação Básica juntamente aos licenciandos e docentes do Ensino Superior, incentiva-se uma melhor reflexão e discussão sobre as atividades desenvolvidas na escola. 
Nessa perspectiva, apresenta-se parte dos resultados de um curso de formação continuada que envolveu professores da Educação Básica de Ciências da Natureza que atuam nos anos finais do Ensino Fundamental e do Ensino Médio, bem como de licenciandos do curso de Ciências Exatas.

\section{Resolução de Problemas no Ensino de Ciências}

A RP como metodologia de ensino, "permite o trabalho pedagogicamente orientado com situações instigantes (problemas), a construção de concepções científicas adequadas e o desenvolvimento de atitudes científicas" (GOI, 2014, p. 31). Assim, para que os discentes utilizem em seu cotidiano os conceitos científicos compreendidos durante a resolução de um problema é necessário o uso desta estratégia metodológica na formação científica (POZO, 1998). Dessa forma, para que os alunos possam solucionar um problema, é preciso trabalhar nesta perspectiva (POZO, 1998).

A RP é uma metodologia ativa, na medida em que envolve os alunos durante o desenvolvimento das atividades para que sejam os principais responsáveis por suas aprendizagens (VALENTE; ALMEIDA; GERALDINI, 2017). Na visão desses autores,

\footnotetext{
as metodologias ativas são estratégias pedagógicas [...] nas quais os alunos passam a ter um comportamento mais ativo, [...] realizando atividades que possam auxiliar o estabelecimento de relações com o contexto, o desenvolvimento de estratégias cognitivas e o processo de construção de conhecimento (VALENTE; ALMEIDA; GERALDINI, 2017, p. 464).
}

No decurso do desenvolvimento desta metodologia, os discentes são instigados a construírem estratégias que os levem a uma resolução. Assim, a RP age como um incentivo, de modo a propiciar a aprendizagem através da construção de competências para resolver determinada situação (SOUZA; DOURADO, 2015). Em consonância, Echeverría e Pozo (1998, p. 14-15) argumentam que, "ensinar a resolver problemas não consiste somente em dotar os alunos de habilidades e estratégias eficazes, mas também em criar neles o hábito e a atitude de enfrentar a aprendizagem como um problema para o qual deve ser encontrada uma resposta”.

Leite e Esteves (2006) salientam que a aprendizagem baseada em problemas se caracteriza como uma metodologia de ensino que induz os alunos ao aperfeiçoamento intelectual, à medida que desenvolve por meio do trabalho em conjunto, a comunicação, a socialização, o apoio entre colegas e o respeito mútuo. Dessa forma, ao solucionar problemas, o discente 
pode ir adiante do aprimoramento cognitivo, desenvolvido durante a formulação de hipóteses; ele também abarca valores afetivos e sociais importantes, pois ao socializar com os demais alunos, surge um ambiente propício à discussão, no qual o discente acaba por aprender a ouvir e a refletir sobre diferentes pontos de vista, contribuindo assim para sua autoestima (BATINGA, 2010).

Por meio da RP o aluno pode desenvolver a capacidade de construir caminhos que o levem à construção de conhecimento, e de demonstrar esse processo construtivo, por meio de atitudes, conceitos, argumentos e exemplificações estruturadas durante a intervenção com professores e colegas (COSTA; MOREIRA, 2001). Assim como ocorre nos processos investigativos, as respostas obtidas pelos alunos podem levar a novos problemas, fazendo-se necessário que os estudantes, bem como os professores, considerem esse entendimento como um aspecto importante da RP, dando enfoque à criatividade (GIL PÉREZ et al., 1992). Essa proposição também é ressaltada por Pozo (1998, p. 9) quando destaca que

o ensino baseado na solução de problemas tem como pressuposto promover nos alunos o domínio de habilidades e estratégias que lhes permitem aprender a apreender, assim como a utilização de conhecimentos disponíveis para dar respostas a situações variáveis e diferentes.

Dessa forma, é necessário que o professor leve em consideração a participação dos discentes durante o processo de investigação, dando atenção para as ações realizadas na elaboração da resposta, e ainda é preciso que o docente dê importância não somente ao seguimento do trabalho, mas também à forma com que os discentes raciocinam, bem como a capacidade de resolver problemas e elaborar caminhos para soluções (WILSEK; TOSIN, 2012).

Cabe ao professor, apto a desenvolver a metodologia, a função de conduzir os alunos, de forma a qualificá-los para que desenvolvam, a partir da pesquisa, a capacidade de elaborar caminhos para resolver problemas (PEDUZZI, 1997). Nesse sentido, Soares e Pinto (2001) destacam que o professor tem a responsabilidade de incentivar, estruturar e mediar as hipóteses trazidas pelos estudantes, contribuindo para que os alunos consigam organizar as informações obtidas. Goi (2004, p. 57) complementa que o professor "deve estimular situações que propiciem uma aprendizagem através do pensar, do refletir, objetivando novos conceitos".

Echeverría e Pozo (1998) explicam que na ausência de métodos eficientes, sejam eles habilidades ou estratégias trabalhadas pelo professor, o estudante falhará na tentativa de resolver problemas. Nesse sentido, Batinga (2010, p. 34) revela que: 
Ao trazer para a sala de aula problemas a serem resolvidos o professor está criando potencialmente condições para que os alunos elaborem hipóteses, busquem conhecimentos já produzidos acerca do que estão estudando, realizem experimentos tanto para testar suas hipóteses, como para entender os conhecimentos já produzidos.

Alguns autores como Nery e Maldaner (2012) e Fejes et al. (2008) apontam sobre a relevância em incentivar a autoria nos docentes ao produzir seu material didático e isso pode ser realizado através da formação de professores.

Para Lopes (1994), o entendimento sobre problema de investigação didática é difícil e precisa, principalmente, da interpretação teórica de quem observa o problema, tendo diversos fatores a serem levados em consideração para resolvê-lo, como: o enredo do problema, as técnicas de abordagem necessárias, as possíveis soluções, entre outras. Todavia, o autor menciona que os problemas podem ser considerados "algo em que não se conhece a resposta nem se sabe se existe - possuem vários níveis de complexidade - podem possuir modelos diversos no formato tradicional de papel e lápis" (LOPES, 1994, p. 24).

No entanto, Pozo (1998) especifica que uma situação só será considerada um problema quando for reconhecida como tal. Assim, um problema, na visão do autor, é caracterizado na dimensão em que não se obtêm processos imediatos que possibilitem solucioná-lo de forma rápida, sem que o aluno tenha a necessidade de refletir ou de tomar decisões a respeito de como proceder para que consiga obter uma resposta a determinada indagação.

Na interpretação de Lopes (1994), um problema pode ser utilizado para aprimorar estratégias de raciocínio, possibilitar o desenvolvimento de conceitos e conhecimentos, enquanto que, exercícios devem ser usados para instrumentalizar determinado conteúdo, aprimorar técnicas, regras, leis, bem como exemplificar conteúdos escolares. Da mesma maneira, pode-se ressaltar que por meio da RP é possível extinguir o imediatismo e incitar a reflexão e o entendimento das circunstâncias, fatos que não são vistos ao se resolver exercícios (LOPES, 1994).

Nesse processo, a solução habitual de exercícios geralmente não envolve uma análise qualitativa, esse fato se dá devido aos exercícios ou questões trabalhadas pelo professor, e que geralmente encontram-se nos livros didáticos, não representarem um problema para o estudante (CLEMENT; TERRAZZAN, 2011). Os autores explicam que esses exercício ou questões, quando problematizados e reformulados pelo docente para que envolvam aspectos do contexto do aluno, são transformados de simples exercícios para um problema que o aluno 
terá que encontrar uma solução, integrando o processo de aprendizagem, não ficando limitado a uma verificação dos conceitos expostos nas aulas. Faz-se necessário, então, que o docente compreenda os limites entre problema e exercícios e que expresse aos alunos as exigências tratadas durante a RP (POZO, 1998).

Em consonância com o exposto, Pozo (1998) ainda argumenta que quando o aluno tem contato com uma atividade pela primeira vez, ela pode se caracterizar como um problema, mas na medida em que o professor repete a mesma atividade diversas vezes, esse aluno acabará concebendo esse trabalho como um exercício. Assim, "quando a prática nos proporcionar a solução direta e eficaz para a solução de um problema, escolar ou pessoal, acabaremos aplicando essa solução rotineiramente, e a tarefa servirá, simplesmente, para exercitar habilidades já adquiridas" (POZO, 1998, p. 17).

Para Costa e Moreira (1997), quando as atividades escolares são conduzidas em circunstâncias objetivas e fechadas, induzem os discentes a desenvolverem suas atividades de maneira automática, sem que seja necessário buscar por informações, formular hipóteses, fazer associações, ou seja, com uma necessidade mínima de envolver-se no processo. Quanto mais abertas ou novas forem as atividades envolvendo problemas, maior será o aprimoramento cognitivo do aluno, visto que os problemas abertos são considerados uma potencialidade para a construção do conhecimento, bem como relacionar outros contextos, influenciando para que o aluno se torne protagonista de seu aprendizado (POZO, 1998; WATTS, 1991).

Desenvolver a metodologia de RP no ambiente escolar em longo prazo faz com que os alunos se acostumem a solucionar problemas e formular estratégias. Assim, "ensinar ao aluno a resolver problemas consiste não apenas em ensinar-lhe estratégias eficazes, mas em criar-lhe o hábito e a atitude de encarar a aprendizagem como um problema para o qual se tem que encontrar respostas" (POZO, 1998, p. 15). Com intenção de viabilizar esse processo é interessante trabalhar com os discentes a RP desde a educação primária até os anos finais da Educação Básica (COSTA; MOREIRA, 1997).

Segundo Lopes (1994), a RP é constituída de fases em que a solução não se dá de forma linear e sequencial. No entanto, para viabilizar esse trabalho é possível fornecer indicações e técnicas gerais que guiem o aluno durante o processo de resolução. Nesse sentido, Zuliani e Ângelo (2001) expõem uma sequência didática, com o intuito de viabilizar e facilitar o desenvolvimento dos problemas nos contextos escolares. Para os autores é necessário: i) 
Apresentar o conteúdo relacionado ao problema que será resolvido; ii) propor o problema e instaurar um processo de pesquisa, bem como preparar as atividades práticas; iii) Resolver o problema; iv) Socializar e analisar as diferentes estratégias adotadas pelos grupos; e, v) Produzir relatórios.

Os problemas implementados no Ensino de Ciências podem ter diferentes classificações. Segundo Pozo (1998), os problemas escolares podem ser classificados em qualitativos, quantitativos e pequenas pesquisas. Os problemas qualitativos são caracterizados por problemas em que os alunos precisarão se apropriar de conceitos teóricos, de modo a vinculálos aos seus conhecimentos prévios para resolver determinada situação, sem a necessidade de utilizarem de contas matemáticas para chegar à sua solução; nos problemas quantitativos, os discentes necessitarão fazer usos de dados numéricos para obter a resposta, sendo fundamentado por cálculos matemáticos e fazendo uso de fórmulas; os problemas de pequenas pesquisas são uma aproximação à Ciência, em que o aluno terá que realizar um trabalho prático, formular hipóteses e traçar estratégias para alcançar a solução do problema (POZO, 1998).

Echeverria e Pozo (1998) classificam os problemas de acordo com a sua natureza, podendo ser teórico, experimental e teórico versus experimental. Já Watts (1991) traz uma classificação dicotômica, podendo ser: aberto-fechado, formal-informal, curricular-não curricular, livre-orientado, dado-apropriado e reais-artificiais. Para o autor, problemas abertos são caracterizados por possuírem diversos caminhos que podem levar a várias soluções; nos fechados só é possível um caminho que, consequentemente, leva a apenas uma solução. Problemas informais são aqueles que muitas vezes não possuem seu contexto claro e que podem surgir por meio de uma problematização, tendo sua formulação muitas vezes não escrita, surgindo no momento da aula; os problemas formais são os problemas pensados pelo docente com antecedência e desenvolvem-se de acordo com o planejamento do professor. Os problemas curriculares são aqueles que abordam o conteúdo que está no currículo, sendo pensados para serem trabalhados em aula como tarefa escolar; os problemas não curriculares são problemas que não estão correlacionados diretamente com os conceitos que devem ser tratados na escola. Um problema livre caracteriza-se por não indicar nenhum tipo de abordagem e não ser dada nenhuma dica ou ajuda para que os alunos possam chegar a sua resolução. Problemas orientados são aqueles em que o problema envolva sugestões que contribuam para a sua solução, tendo assim, suas características opostas aos problemas livres. Os problemas dados diferenciam-se por serem apresentados pelo professor sem que o 
estudante tenha contribuído para sua formulação, assim como aqueles problemas que não vão ao encontro dos interesses do aluno. Nos problemas aprimorados, o aluno tem alguma participação em sua construção, de modo a sentir-se parte do processo de construção. Nos problemas reais são abordados conceitos envolvidos com a realidade da sociedade; os artificiais não estão vinculados com interesses da sociedade, sendo desenvolvidos para colaborar com interesses escolares (WATTS, 1991).

Lopes (1994) esclarece que essas proposições são estabelecidas para situações bem definidas, podendo ser encontrados problemas que sejam intermediários entre as categorias.

\section{Metodologia e contexto da pesquisa}

Esse trabalho é de cunho qualitativo. Os dados coletados são descritivos e há uma maior preocupação com o processo do que com o produto final (LÜDCKE; ANDRÉ, 1986). Os conjuntos de dados coletados foram produzidos em espaços de discussão: na universidade e nas escolas da Educação Básica. Neste texto apresenta-se e discute-se os problemas que foram produzidos pelos professores em curso de formação.

Para tanto, foram elaborados Diários de Campo (PORLÁN; MARTíN, 1998), nos quais os pesquisadores realizaram o registro das observações mais significativas do processo formativo e foram realizadas gravações de áudio de toda a ação extensionista. Os professores em formação assinaram um Termo de Consentimento Livre e Esclarecido permitindo a utilização dos áudios como fonte de pesquisa. Neste trabalho não há um aprofundamento das falas dos extensionistas, esse aprofundamento está detalhado em outros artigos dos autores, aqui se discute os problemas produzidos a partir do que a literatura apresenta.

O curso aconteceu semanalmente durante os meses de setembro de 2017 a junho de 2018 nas dependências da Unipampa, contabilizando 50 horas de formação e foi coordenado por 3 docentes da mesma universidade da área de ensino de Química. Os professores implementaram suas propostas nas diferentes escolas públicas da Educação Básica nos municípios de Caçapava do Sul e Vila Nova do Sul, no Rio Grande do Sul. O grupo se constituiu por sete professores, cinco em formação continuada, formados em Ciências da Natureza (Química e Biologia) e professores da rede pública dos anos finais do Ensino Fundamental e do Ensino Médio e dois professores em formação inicial do curso de Licenciatura em Ciências Exatas da Unipampa, campus Caçapava dos Sul. 
A ação de extensão aconteceu em três módulos. No primeiro módulo, foi realizado um aprofundamento conceitual sobre as obras dos autores que trabalham sobre os aspectos epistemológicos (Laudan), pedagógicos (Dewey) e psicológicos (Bruner). Além disso, foi apresentada uma revisão de literatura sobre RP na formação de professores. No segundo módulo, os professores produziram seu próprio material didático que foi apresentado e avaliado pelos professores formadores do curso de extensão. Seguida a essa produção, os problemas foram implementados pelos extensionistas nos contextos de suas salas de aula. No terceiro e último módulo da ação de extensão, os professores extensionistas trouxeram os resultados de suas implementações, os quais foram apresentados ao grupo em forma de plenária.

Neste artigo são discutidos parte dos problemas produzidos pelos professores no segundo módulo da ação extensionista.

\section{Análise e discussão dos resultados: os problemas produzidos pelos professores em curso de extensão}

A elaboração e construção de problemas permite que os professores em formação se apropriem do referencial teórico que envolve a metodologia de RP, uma vez que é necessário o seu aprofundamento para a compreensão da estruturação de um problema e dos aspectos que o diferenciam de um exercício. Dessa forma, o professor reconhece as características que devem ser levadas em consideração para que o problema aproxime-se das competências que almeja trabalhar com seus alunos, conduzindo, assim, para um trabalho mais objetivo e orientado.

Os docentes produziram individualmente seus blocos de problemas e alguns professores optaram pela construção de mais de um bloco.

No Apêndice A deste trabalho, apresentamos um recorte dos blocos de problemas construídos durante a formação. A relação completa dos blocos de problemas produzidos pode ser obtida no trabalho de Siqueira (2018). Para a preservação da identidade dos professores, eles foram identificados pela letra D seguida das letras em ordem alfabética do A ao G. Os problemas são identificados pela letra $\mathrm{P}$ e apresentados em blocos.

Os problemas foram avaliados por três professores da universidade durante a plenária de apresentação no curso de formação. Todas as atividades construídas pelos docentes foram 
identificadas pelos professores da banca de avaliação como problemas e alguns caracterizados por pequenas pesquisas.

No decorrer da exposição dos professores extensionistas, pôde-se evidenciar que a maioria tem conhecimento sobre a necessidade de organizar os problemas em ordem crescente de dificuldade conceitual, ou seja, inicia-se pelo problema mais fácil, respeitando o grau de dificuldade de cada um (BRUNER, 1966), bem como construir os problemas em blocos que se relacionam por meio de um conteúdo ou temática que trata sobre a experiência local (DEWEY, 2010). Isso pode ser evidenciado no excerto a seguir:

[...] o mesmo raciocínio que eu segui aqui nos meus, primeira coisa eu falei sobre digestão, e depois eu coloquei todos os problemas se relacionando, por que daí era um bloco de problema, por isso que a minha intenção é essa, primeiro eu falei do que envolvia o problema, eu falei do todo e depois eu fui colocando os problemas todos referentes ao mesmo assunto. $\left(D_{B}\right)$.

Outra professora relata que, por não ter experiência com a metodologia de RP, acaba por não levar em consideração a construção dos problemas por ordem de complexidade de conteúdo no momento de estruturá-los, mas manifestou ter conhecimento da importância desse processo. Desse modo, percebe-se pelo exposto que os docentes seguiram as concepções de Bruner (1966; 2008) quando sinalizam que o currículo escolar está organizado em formato de espiral, ou seja, os conceitos pertencentes ao currículo devem ser estudados ao longo de anos, em níveis crescentes de complexidade, voltando aos conteúdos já trabalhados. Essa atitude, por parte dos professores em formação, parece evidenciar a compreensão e preocupação em utilizar o referencial teórico trabalhado durante a formação, e a importância dos professores formadores destacarem os conceitos que envolvem a metodologia durante o processo formativo.

Outro aspecto apontado refere-se à dificuldade em construir blocos de problemas, seguindo uma sequência de temáticas e conteúdos selecionados, isso pode ser evidenciado no seguinte excerto: "É difícil, principalmente produzir um bloco de problemas. Um problema separado com um tema não é tão difícil, a dificuldade é juntar os problemas" $\left(\mathrm{D}_{\mathrm{D}}\right)$.

Conforme esse excerto fica evidente que a construção de problemas se caracteriza como um trabalho árduo que requer esforço e conhecimento sobre a metodologia, isso já foi sinalizado por Dewey (2010) quando ele aponta que o processo de aprender exige esforço. Nesse sentido, a RP aliada à formação docente pode preparar o professor, fornecendo-lhe instrumentos para que, mesmo com dificuldade, crie o hábito para desenvolver seu próprio 
material didático tornando-se mais autônomo em suas atividades. Nery e Maldaner (2012) e Fejes et al. (2008) ressaltam a relevância em incentivar a autoria nos docentes em produzirem seu material didático e promover que esses professores consigam desenvolver, principalmente, a capacidade de refletir e serem autônomos sobre seus trabalhos docentes, levando em consideração a experiência de cada aluno ao produzir o material didático (DEWEY, 2010).

Durante a avaliação dos problemas, os apontamentos realizados pelos professores formadores referem-se à falta de clareza dos mesmos, pois muitos dos trabalhos apresentados não deixam claro os objetivos a serem alcançados na produção do bloco de problemas. Esse é um aspecto que os docentes devem estar atentos, pois os objetivos a serem alcançados durante a atividade devem estar explícitos para os alunos (GOI, 2004; 2014). Outro aspecto sinalizado pelos docentes em formação se refere a não estarem cientes se o que haviam construído se constitui realmente como um problema, como destacado pela professora $\mathrm{D}_{\mathrm{F}}$ "nunca fiz problema, não sei se é realmente um problema ou um exercício" $\left(D_{\mathrm{F}}\right)$.

Mesmo com a fala expressando dúvida, a docente conseguiu elaborar problemas. Esse fato parece demonstrar o entendimento dos professores extensionistas sobre a metodologia que pode ser justificado pelo estudo realizado em referenciais que envolvem a RP e explicações disponibilizadas pelos professores formadores durante o curso, além do fato de alguns docentes já terem contato com o procedimento didático em cursos de mestrado e no Programa Institucional de Bolsas de Iniciação à Docência (PIBID).

Os professores extensionistas levaram em consideração os aspectos teóricos de Laudan (1977) tratados na formação quando sinalizam que a ciência se desenvolve a partir da RP. Isso pode ser evidenciado na fala da professora $\mathrm{D}_{\mathrm{A}}$ quando aponta que "a ciência se desenvolve quando há problemas resolvidos socialmente".

Durante o processo formativo os professores produziram problemas e eles podem ser classificados de acordo com os referenciais da área. A classificação apresentada nesse artigo é analisada a partir dos referenciais de Watts (1991), Lopes (1994), Echeverría e Pozo (1998,), Pozo (1998). Para a análise das situações-problema levam-se em consideração as seguintes classificações: (i) Natureza do problema em teórico, experimental ou teórico versus experimental; (ii) Aberto-fechado; (iii) Formal-informal; (iv) Curricular-não curricular; (v) Livre-orientado; (vi) Dado-apropriado; (vii) Reais-artificiais. Ainda é possível classificar os problemas em interdisciplinares, assim como problemas que abordam temáticas específicas. 
Dos 38 problemas produzidos no trabalho de Siqueira (2018), 42,10\% correspondem a problemas que abordam além de conceitos teóricos, aspectos experimentais. Nesse sentido, Goi (2004) complementa que as atividades experimentais quando aliadas à RP promovem a oportunidade aos alunos aprimorarem seus conhecimentos, na medida em que exercitam a criatividade e mobilizam suas habilidades meio a um trabalho teórico e prático. Entretanto, pouco mais de $50 \%$ dos problemas produzidos referem-se a problemas teóricos. A prevalência por problemas teóricos parece estar relacionada à estrutura física, já que em muitas escolas há falta de laboratórios, falta de equipamentos, vidrarias, reagentes e técnicos, fato que acaba dificultando o trabalho experimental na Educação Básica. Isso já foi apontado em Goi (2004).

Analisando cada bloco de problemas, observa-se que os problemas P1, P9, P13, P14, P15, P28, P32, P37 e P38 são fechados, tendo apenas uma única solução (WATTS, 1991). Percebe-se que 76,31\% caracterizam-se como problemas abertos, ou seja, apresentam duas ou mais soluções. Os problemas abertos destacam-se pelo potencial que possuem para a construção de conhecimento. Assim, o predomínio de problemas abertos demonstra que os professores parecem reconhecer essa importância, bem como buscam que seus alunos aprimorem seus conhecimentos de uma forma mais intensa, como já observado anteriormente em Pozo (1998) e Watts (1991) quando afirmam que os problemas abertos exigem do aluno um maior esforço intelectual, possibilitando aprendizagem de forma mais expressiva durante a tomada de decisões que terá que desempenhar.

Os problemas analisados classificam-se como dado e formal (WATTS, 1991), pois foram elaborados pelos professores em formação, havendo a necessidade de que todas as situaçõesproblema fossem pensadas com antecedência para que, posteriormente, pudessem ser aplicadas na escola, portanto, os alunos não participaram da gênese dos problemas.

Quanto à classificação livre ou orientado (WATTS, 1991), sinaliza-se que todos os problemas foram orientados. A orientação do professor durante a RP é um fator importante, pois é por meio dela que os alunos conseguirão organizar seus conhecimentos para construir suas hipóteses. Tal afirmação é lembrada nesse trabalho por Soares e Pinto (2001, p. 7), em que destacam que o papel do professor durante a atividade com RP "será de incentivador, facilitador, mediador das ideias apresentadas pelos alunos, de modo que estas sejam produtivas, levando os alunos a pensarem e a gerarem seus próprios conhecimentos”.

Outro tipo de problema produzido no curso de formação refere-se aos curriculares, que recebem essa denominação por conterem em sua estruturação conteúdos escolares. Esses 
problemas representam $89,47 \%$ e abordam conteúdos relacionados às soluções, química orgânica, descarte de resíduos químicos e seus impactos ambientais, $\mathrm{pH}$, polaridade das ligações, reações químicas, separação de misturas, radiação UV, termoquímica, sistema digestório, enzimas, absorção calórica, alimentação e nutrição. Apenas 10,52\% dos problemas apresentados não possuem relação com os conteúdos escolares, dando ênfase a aspectos culturais e sociais, como pode ser observado no P7, o qual questiona sobre os diferentes tipos de azeite de oliva e seus respectivos benefícios à saúde, levando os alunos a pensarem sobre produtos que podem contribuir para uma boa alimentação. A baixa produção de problemas do tipo não-curriculares parece estar relacionada à preocupação que os docentes têm em "vencer o conteúdo", visto que o tempo de aplicação de um bloco é longo, por isso dão preferência para aplicar problemas que envolvem conteúdos curriculares.

Cerca de 29\% dos problemas produzidos classificam-se segundo Watts (1991) em artificiais, e recebem essa categorização por não apresentarem vínculo com a realidade dos alunos, abordando apenas conceitos escolares. Assim, a maioria dos problemas produzidos estão relacionados com a realidade dos alunos. É válido destacar a importância que esse tipo de problema possui, na medida em que contribui para que os alunos se tornem mais críticos sobre aspectos de sua realidade. Dewey (2010) aponta que envolver a realidade dos estudantes em atividades educativas, pode auxiliar para o desenvolvimento pessoal contribuindo para a formação de cidadãos críticos e conscientes sobre assuntos da sua realidade.

Dentre os problemas classificados como reais (WATTS, 1991), identifica-se a presença de blocos envolvendo temáticas específicas. Esses problemas representam 57,89\% em que foram abordadas temáticas referentes ao Meio Ambiente, Temas Locais e Saúde. As temáticas colaboram para o desenvolvimento da educação para a cidadania, na medida em que tratam, na escola, problemas do cotidiano. Dessa maneira "muitas questões sociais poderiam ser eleitas como temas transversais para o trabalho escolar, uma vez que o que os norteia para a construção da cidadania e a democracia, são questões que envolvem múltiplos aspectos e diferentes dimensões da vida social" (BRASIL, 1997, p. 25). Isso também é evidenciado em Dewey (2010), quando sinaliza que se deve trabalhar com temáticas relevantes, considerando a experiência de vida de cada indivíduo.

Entre os problemas analisados $36,84 \%$ configuram-se como problemas disciplinares, abordando apenas uma disciplina escolar. Assim, 63,15\% dos problemas produzidos no curso de extensão caracterizam-se como problemas interdisciplinares em que envolvem, ao mesmo 
tempo, mais de uma disciplina escolar. Dentre os problemas interdisciplinares encontram-se os que abordam conceitos evolvendo as disciplinas de Ciências da Natureza (Química, Física e Biologia) e Geografia, Química, Biologia e Geografia; Química e Física; Química e Biologia; Química, Biologia e Educação Física; Ciências da Natureza; Ciências, Geografia, História e Economia; Biologia e História. Assim, observa-se um predomínio de atividades interdisciplinares. Esse tipo de atividade é importante, pois, por meio da integração de várias áreas do conhecimento, viabiliza-se a compreensão dos estudantes, tanto para os conteúdos escolares quanto para o mundo em que vivem, isso corrobora com os pressupostos de Dewey (2010), quando destaca que se deve tratar das experiências de vida de cada estudante.

A prevalência de problemas abertos, curriculares, reais, interdisciplinares e que abordam temáticas importantes para a sociedade, demonstra a preocupação dos professores em proporcionar aos alunos uma melhor compreensão dos conceitos tratados na escola, assim como prepará-los para resolver situações-problema dos seus cotidianos.

Em contraponto, menos da metade dos problemas produzidos são de natureza teórica versus experimental, como apresenta Echeverria e Pozo (1998), aspecto esse que deve ser trabalhado de forma mais intensa pelos professores da área de Ciências da Natureza, mas que não são, possivelmente devido a dificuldades referentes à falta de materiais e de espaço físico adequado, dificuldades estas muitas vezes encontradas na Educação Básica, acaba comprometendo a implementação deste tipo de problema.

\section{CONSIDERAÇÕES FINAIS}

A construção dos blocos de problemas, pelos professores, parece ter possibilitado o aperfeiçoamento da autonomia e reflexão docente, bem como apropriação sobre os aspectos que caracterizam os problemas. Para Goi (2014) na medida em que os docentes constroem problemas eles devem pensar nos conceitos que desejam trabalhar, nas soluções que os alunos poderão chegar, nas dificuldades que poderão enfrentar durante a sua aplicação, nas competências que almejam desenvolver e nas diferentes ferramentas necessárias para que os alunos construam suas hipóteses. Esses aspectos levam, principalmente, para o aprimoramento da reflexão sobre a prática em sala de aula, bem como para a construção da autonomia acerca de seu trabalho docente, visto que o professor será o autor do seu material didático (NERY; MALDANER, 2012; FEJES et al., 2008). 
O curso de formação parece ter contribuído para aperfeiçoar os conhecimentos dos docentes, oportunizado em diversos momentos, a partir de discussões, estudos, troca de experiências, explicações entre professores da Educação Básica, licenciandos e professores da Educação Superior. Assim, fortalece as concepções de Libâneo e Pimenta (1999) que trazem a ideia de que a formação continuada pode ser realizada na universidade articulada à formação inicial, estimulando uma melhor reflexão e discussão sobre as atividades desenvolvidas na escola.

Desse modo, conclui-se que os objetivos deste trabalho foram alcançados, pois durante a análise dos problemas, pode-se identificar que o curso de formação possibilitou aos docentes ampliar o conhecimento sobre os aspectos que caracterizam os problemas, visto que os professores conseguiram construir blocos de problemas com certa destreza abordando conceitos e temáticas. E, ainda, que, por meio dos relatos das implementações dos problemas na Educação Básica, os professores parecem desenvolver as atividades conforme orientações disponibilizadas no curso de formação, bem como reconhecem a RP como uma metodologia a ser utilizada no contexto de sala de aula.

\section{REFERÊNCIAS}

ABREU, M. C. S. Formação continuada: uma reflexão sobre a resignação da prática docente. 2006. Dissertação (Mestrado em Educação) - Universidade Federal do Rio de Janeiro, Rio de Janeiro, 2006.

BATINGA, V. T. S. A abordagem de RP por professores de química do ensino médio: um estudo de caso sobre o conteúdo de estequiometria. Tese (Doutorado em Educação) Universidade Federal de Pernambuco, Recife, 2010.

BENTLIN, F. R. S. RP como prática de ensino sobre funções inorgânicas para alunos da EJA. Trabalho de Conclusão de Curso (Licenciatura em Ciências Exatas) - Instituto de Química, Universidade Federal do Rio Grande do Sul, Porto Alegre, 2009.

BOLZAN, E. C. V. M. M. RP como proposta para o ensino e aprendizagem de física moderna e contemporânea no ensino médio. Trabalho de Conclusão de Curso (Licenciatura em Ciências Exatas) - Universidade Federal do Pampa, Caçapava do Sul, 2015.

BOLZAN, T. D. Ensino da função polinomial do $2^{\circ}$ grau através da metodologia da RP. Trabalho de Conclusão de Curso (Licenciatura em Ciências Exatas) - Universidade Federal do Pampa, Caçapava do Sul, 2015.

BRASIL. Ministério da Educação. Secretaria de Educação Fundamental. Parâmetros Curriculares Nacionais. Brasília: MEC/SEF, 1997.

BRUNER, J. S. Uma nova teoria da aprendizagem. Rio de Janeiro: Block, 1966.

BRUNER, J. S. Sobre o conhecimento: ensaios de mãos esquerda. São Paulo: Phorte, 2008. 
CARRER, E. L. B. A RP como estratégia para o estudo da química no cotidiano. Trabalho de Conclusão de Curso (Licenciatura em Química) - Instituto de Química, Universidade Federal do Rio Grande do Sul, Porto Alegre, 2008.

CLEMENT, L.; TERRAZZAN, E. A. Atividades didáticas de RP e o ensino de conteúdos procedimentais. Revista electrónica de investigación em educación em ciencias, Buenos Aires, v. 6, n.1, p. 87-101, 2011.

COSTA, S. S. C., MOREIRA, M. A. RP II: propostas de metodologias didáticas. Investigações em Ensino de Ciências, Porto Alegre, v. 2, n. 1, p. 5-26, 1997.

COSTA, S. S. C.; MOREIRA, M. A. A RP como um tipo especial de aprendizagem significativa. Caderno Catarinense de Ensino de Física, Florianópolis, v. 18, n. 3, p. 263277, 2001.

DEWEY, J. Experiência e educação. Tradução de Renata Gaspar. Petrópolis, RJ: Vozes, 2010.

ECHEVERRÍA, M. D. P; POZO, J. I. Aprender a resolver problemas e resolver problemas para aprender. In: POZO, J. I. (org.). A solução de problemas: aprender a resolver, resolver para aprender. Porto Alegre: ArtMed, 1998. p. 13-42.

FREITAS, J.Q.P. RP no ensino da matemática: uma introdução à geometria fractal no ensino fundamental. Trabalho de Conclusão de Curso (Licenciatura em Ciências Exatas) Universidade Federal do Pampa, Caçapava do Sul, 2015.

GIL PÉREZ, D. et al. Questionando a didática de RP: elaboração de um modelo alternativo. Caderno Catarinense de Ensino de Física, Florianópolis, v. 9. n. 1. p. 7-19, 1992.

GOI, M. E. J. A Construção do conhecimento químico por estratégias de RP. Dissertação (Mestrado em Ensino de Ciências e Matemática) - Universidade Luterana do Brasil, Canoas, 2004.

GOI, M. E. J. Formação de professores para o desenvolvimento da metodologia de RP na educação básica. Tese (Doutorado em Educação) - Universidade Federal do Rio Grande do Sul, Porto Alegre, 2014.

LAUDAN, L. Progress and it's problems: towards a theory of scientific growth. London: outledge \& Kegan Pau, 1977. p. 275.

LEITÃO, Á.; ALARCÃO, I. Para uma nova cultura profissional: uma abordagem da complexidade na formação inicial de professores do $1^{\circ}$ CEB. Revista Portuguesa de Educação, Braga, v. 19, n. 2, p. 51-84, 2006.

LEITE, L.; ESTEVES, E. Trabalho em grupo e aprendizagem baseada na RP: um estudo com futuros professores de física e de química. In: Actas do International Conference PBL. Perú: Pontifícia Universidad Católica del Perú, 2006.

LEITE, S. B. Estudo sobre polímeros através da RP. Trabalho de Conclusão de Curso (Licenciatura em Química) - Instituto de Química, Universidade Federal do Rio Grande do Sul, Porto Alegre, 2009. 
LIBÂNEO, J.; PIMENTA, S. Formação de profissionais da educação: visão crítica e perspectiva de mudança. Educação e Sociedade, Campinas, ano XX, n. 68, p. 239-277, 1999. Doi: 10.1590/S0101-73301999000300013.

LOPES, J. RP em física e química. Lisboa: Texto, 1994.

LÜDCKE, M.; ANDRÉ, M. Pesquisa em educação: abordagens qualitativas. São Paulo: EPU, 1986.

NERY, B, K.; MALDANER, O. A. Formação continuada de professores de química na elaboração escrita de suas aulas a partir de um problema. Revista Electrónica de Enseñanza de las Ciencias, Vigo, v. 11, n. 1, p. 120-144, 2012.

PEDUZZI, L. O. Q. Sobre a RP no ensino da Física. Caderno Catarinense de Ensino de Física, Florianópolis, v. 14, n. 3, p. 229-253, 1997.

PERES, R. G. Análises e reflexões sobre o uso da RP como alternativa metodológica para o ensino de química no ensino técnico. Trabalho de Conclusão de Curso (Licenciatura em Química) - Instituto de Química, Universidade Federal do Rio Grande do Sul, Porto Alegre, 2015.

PORLÁN, R.; MATÍN, J. El diário del professor: un recurso para la investigación em el aula. 4. ed. Sevilla/ESP: Díada, 1994. (Colección Investigación y Enseñaza, Serie Práctica).

POZO, J. I. (org.). A solução de problemas: aprender a resolver, resolver para aprender. Porto Alegre: Artmed, 1998.

SANTOS, A. B. RP como prática de ensino de funções inorgânicas. Trabalho de Conclusão de Curso (Licenciatura em Química) - Instituto de Química, Universidade Federal do Rio Grande do Sul, Porto Alegre, 2009.

SILVA, E. A. Articulação entre RP e a temática drogas como proposta metodológica para o ensino de química. Trabalho de Conclusão de Curso (Licenciatura em Ciências Exatas) - Universidade Federal do Pampa, Caçapava do Sul, 2017.

SIQUEIRA, V. F. RP na formação de professores de ciências da natureza: aspectos pedagógicos e metodológicos. Trabalho de Conclusão de Curso (Licenciatura em Ciências Exatas) - Universidade Federal do Pampa, Caçapava do Sul, 2018.

SOARES, M. T. C., PINTO, N. B. Metodologia da Resolução de Problemas. In: REUNIÃO ANPED, 24., 2001. Disponível em: http://24reuniao.anped.org.br/tp1.htm. Acesso em: 15 maio 2019.

SOUZA. R. L. L. Formação continuada dos professores e professoras do município de Barueri: compreendendo para poder atuar. Dissertação (Mestrado em Educação) Universidade de São Paulo, São Paulo, 2007.

SOUZA, S. C.; DOURADO, L. Aprendizagem baseada em problemas (ABP): um método de aprendizagem inovador para o ensino educativo. HOLOS, Natal, Ano 31, v. 5. p. 182-200, 2015. Doi: 10.15628/holos.2015.2880. 
VALENTE, V. A.; ALMEIDA, M. E. B.; GERALDINI, A. F. S. Metodologias ativas: das concepções às práticas em distintos níveis de ensino. Revista Diálogo Educacional, Curitiba, v. 17, n. 52, p. 455-478, 2017. Doi: 10.7213/1981-416X.17.052.DS07.

WATTS, M. The science of problem-solving-a pratical guide for science teachers. London: Cassell, 1991.

WILSEK, M.; TOSIN, J. Ensinar e aprender ciências no ensino fundamental com atividades investigativas através da RP. Dia a Dia e Educação, Curitiba, v. 3, n. 5, 2012.

ZULIANI, S. R. Q. A; ÂNGELO, A. C. D. A utilização de metodologias alternativas: o método investigativo e a aprendizagem de química. In: NARDI, R. (org.). Educação em ciências: da pesquisa à prática docente. São Paulo: Escrituras, 2001. p. 69-80.

Submetido em 13 de maio de 2019.

Aprovado em 11 de julho de 2019. 


\section{Apêndice A - Recorte de blocos de problemas produzidos pelos professores em Formação e suas classificações}

\begin{tabular}{l} 
Problemas \\
\hline Bloco I- Professor $\mathrm{D}_{\mathrm{A}}$ \\
P1. Um solvente é uma substância que pode dissolver outras moléculas e compostos, que são conhecidos \\
como solutos. Uma mistura homogênea de solvente e soluto chama-se solução e boa parte da química da vida \\
ocorre em soluções aquosas, ou soluções em que a água é o solvente. Dois mecânicos após concluírem seu \\
turno de serviço foram fazer a limpeza de suas mãos, o primeiro utilizou-se de água para remover os resíduos \\
de graxa, já o segundo utilizou-se de gasolina. Os dois obtiveram o mesmo resultado? De acordo com a \\
química como pode ser explicado este resultado? \\
P2. A água é considerada como solvente universal, pois a maioria das reações ocorre em meio aquoso. Mesmo \\
com essa característica ela não consegue dissolver todas as substâncias. Apresente alguns experimentos em \\
que a água funciona como solvente e outros com substâncias que ela não é capaz de dissolver, explicando os \\
resultados. \\
P3. Solução nada mais é do que uma mistura homogênea constituída por duas ou mais substâncias em uma só \\
fase. As soluções são formadas por um solvente, geralmente o componente em maior quantidade e um ou \\
mais solutos em menor quantidade. Uma propriedade importante das soluções é a saturação. Quanto à \\
saturação, as soluções podem ser classificadas em insaturadas, saturadas e supersaturadas. Através de \\
atividades experimentais apresente as diferenças dessas soluções.
\end{tabular}

Bloco II, professor $\mathrm{D}_{\mathrm{A}}$

P6. Moradores do Município de Caçapava do Sul na última década vem investindo em plantações de oliveira, e a partir do ano de 2013 começaram a produzir o "Prosperato", um azeite de oliva extra virgem considerado de excelente qualidade. Existem processos químicos e físicos envolvidos na produção do "Prosperato". Faça uma pesquisa de como ocorre essa produção diferenciando os processos químicos e físicos envolvidos e explique quais fatores lhe garantiram este conceito.

P7. O azeite de oliva é muito consumido principalmente para o tempero de saladas, mas no momento de comprá-lo em um supermercado você poderá encontrar alguns tipos diferentes: o extra virgem, o azeite virgem, o azeite de oliva puro ou natural e o light. Quais as diferenças entre eles? Quais os benefícios que trazem à saúde?

P8. Na pesquisa realizada sobre os tipos de azeite de oliva, você encontrou a sigla $\mathrm{pH}$ que significa potencial hidrogeniônico e consiste num índice que indica a acidez, neutralidade ou alcalinidade de um meio qualquer. Elabore algumas atividades experimentais que lhe possibilitam compreender seu significado e explicá-lo para os colegas.

Bloco IV Professor $\mathrm{D}_{\mathrm{A}}$

P9. Todo dia ao acordar costuma-se fazer a mesma rotina: tomar banho, escovar os dentes enfim praticar seus hábitos de higiene. Você percebe que em todas essas ações há sempre química envolvida. Por exemplo, as pastas de dente assim como os sabonetes são produtos químicos. Conhecer um pouco sobre química pode evitar equívocos e muitas vezes gastos desnecessários bem como impactos ambientais. Você já observou que muitas vezes alguns sabonetes são mais caros por serem especificados como neutros, mas será que existe sabonete totalmente neutro? Se ele for neutro ele cumprirá sua função na limpeza da pele?

P10. Você já se perguntou como os sabonetes são feitos. Pesquise como os sabonetes são produzidos e como eles atuam na higiene do nosso corpo. Faça um experimento demonstrando a produção de sabonetes.

P11. Quando fizemos nossa higiene diária ou a limpeza de nossas casas, fizemos uso de diversos produtos como sabonetes, shampoos, detergentes, etc. Pesquise de que maneira os resíduos da utilização desses produtos impactam no meio ambiente.

Bloco V Professor $\mathrm{D}_{\mathrm{B}}$

P12. A pirâmide alimentar é um tipo de gráfico que mostra quais alimentos devem ser consumidos e a quantidade ideal para uma alimentação saudável. Na pirâmide alimentar todos os alimentos (energéticos, reguladores e construtores) são indispensáveis para o bom equilíbrio e o funcionamento do corpo humano. Qual é o local na pirâmide alimentar em que encontramos os carboidratos e por quê?

P13. Nossa alimentação é bastante variada. Ela é composta por alimentos sólidos e líquidos, nos quais estão presentes vários nutrientes, como carboidratos, gorduras, proteínas, açúcares, vitaminas, sais minerais e água. 
As moléculas quando ingeridas, podem ser absorvidas diretamente pelo tubo digestório. É o que ocorre com moléculas pequenas. Moléculas maiores, no entanto, precisam ser quebradas até se tornarem pequenas o suficiente para serem absorvidas. É o caso do carboidrato, das gorduras das proteínas. A digestão é, portanto, o processo de fragmentação das moléculas dos alimentos até um tamanho tal que permita ser absorvido pelo organismo. Em que alimentos estão presentes carboidratos como o amido e como podemos comprovar experimentalmente?

P14. O processo de digestão tem início na boca, com a mastigação dos alimentos. Enquanto os alimentos vão sendo fragmentados pelos dentes, ele é umedecido pela saliva, que contém uma enzima que transforma o amido em outro material, iniciando-se assim, o processo de digestão. Como podemos comprovar que a digestão tem início na boca?

P15. Os médicos costumam indicar aos pacientes diabéticos, uma redução em seu consumo alimentar de carboidratos. Você saberia dizer por qual razão esse consumo elevado de carboidrato é prejudicial aos pacientes diabéticos?

P16. Uma dieta balanceada é muito importante para manter nosso corpo saudável. Pensando assim, você pode anotar a sua alimentação durante um dia, e fazer os cálculos, baseado em calorias, para observar se você está mantendo seu organismo saudável. Fazer uma tabela listando todos os alimentos ingeridos durante uma semana. Anote a quantidade de calorias de cada um deles, e ao final avalie se esta quantidade ingerida está de acordo com as necessidades ideais para a manutenção de seu organismo. Caso não esteja, proponha ações de forma a equilibrar a quantidade de calorias ingeridas com a quantidade necessária para o bom funcionamento de seu organismo.

Bloco VII Professor $\mathrm{D}_{\mathrm{D}}$

P22. O leite é uma das fontes de cálcio disponível. Por isso, este alimento é essencial para a saúde dos ossos e dentes e seu consumo poderá prevenir a osteoporose. No entanto, algumas pessoas apresentam intolerância à lactose, por não conseguirem digeri-la. Explique porque isso acontece e como deve ser a alimentação de uma pessoa com intolerância à lactose.

P23. A digestão é um processo de quebra dos componentes dos alimentos em moléculas menores, passíveis de absorção e posterior utilização pelo organismo. Alguns compostos, como, por exemplo, colágeno, tende a não sofrer esse processo de degradação durante o processo de digestão. Seu corpo absorve imediatamente, somente a água. Alguns alimentos são digeridos rapidamente, outros podem levar até várias horas, como, por exemplo, as carnes vermelhas, que levam aproximadamente 3 horas para serem digeridas completamente por seu organismo. Por que as pessoas dizem que ao consumir algumas fatias de abacaxi após participar de um farto churrasco ajuda na digestão? Explique como funciona o processo de digestão.

P24. O colágeno é uma proteína que dá estrutura, firmeza e elasticidade à pele, que é produzida naturalmente pelo corpo, mas que também pode ser encontrada em alimentos, como carnes e gelatinas. A gelatina é um alimento muito consumido e é constituída principalmente de proteínas. Dentre as proteínas presentes, a de maior porcentagem é o colágeno. Para prepará-la adicionamos água quente e água fria ao pó da gelatina e logo após levamos a geladeira. Mas porque a gelatina endurece ao ser resfriada? Elabore algum material que ilustre o processo de endurecimento da gelatina.

P25. O ovo é um alimento de origem animal, amplamente consumido e utilizado em diversas receitas. Rico em proteínas, o ovo é também um alimento repleto de outros nutrientes, como as vitaminas A, B, D e E. A ingestão desses nutrientes proporciona a manutenção de uma boa saúde dos olhos, da pele e dos ossos. Ao cozinhar ou fritar um ovo percebemos que sua clara se torna branca. Pesquise a importância desses nutrientes para a manutenção da saúde. Explique conceitualmente e experimentalmente como ocorre a desnaturação das proteínas.

Bloco IX Professor $\mathrm{D}_{\mathrm{E}}$

P28. Todas substâncias que existem se formam através de ligações químicas entre átomos. Existem as ligações iônica, covalente e metálica. Que determina cada uma delas é o tipo de átomos que vão fazer a ligação. A ligação covalente pode ser de dois tipos, polares e apolares. Investigue o que define a polaridade de uma ligação e o porquê dos átomos serem atraídos?

P29. Existem algumas substâncias que se misturam facilmente com outras, e algumas que apresentam mais dificuldade em misturar-se, isso se deve a vários fatores, como por exemplo, polaridade das substâncias. A polaridade de uma substância está relacionada com a formação de polos nas ligações químicas presentes nas substâncias. Proponha um experimento em que podemos identificar substâncias polares e apolares, explique 
teoricamente como você chegou à determinada conclusão.

P30. Existem dois tipos de misturas, as homogêneas e as heterogêneas. As misturas homogêneas são aquelas que apresentam um único aspecto, uma única fase, também chamadas de solução. As misturas heterogêneas são aquelas que apresentam duas ou mais fases. A água da torneira, a água mineral são exemplos de soluções, ou seja, misturas homogêneas. A água que chega as nossas torneiras vem de poços artesianos, rios, cacimbas e para se tornar potável ela deve ser tratada. Proponha um método de separação de misturas adequado para deixar a água potável, própria para o consumo. Demonstre experimentalmente

Bloco X Professor $\mathrm{D}_{\mathrm{F}}$

P31. Paula estuda pela manhã e sempre sai atrasada de casa, por isso nunca toma café antes de sair. Paula sempre apresenta sinais de cansaço e fadiga durante a aula. Sua professora lhe disse que é pela falta de alimento. Explique como a alimentação inadequada interfere no metabolismo humano.

P32. Paula foi ao nutricionista, que lhe deu uma tabela com várias refeições ao longo do dia e com cardápio bem variado, porém, Paula observou que a quantidade de carboidratos era menor do que a de proteínas. Por que o nutricionista fez esse balanceamento ao invés de retirá-los por completo da dieta?

P33. Ao fazer exames de sangue rotineiros, Paula foi surpreendida com seus resultados de altos níveis de glicose, pois, não gosta de comer doces. Como explicar o fato de Paula não comer doces e mesmo assim apresentar um alto nível de glicose?

Bloco XII Professor $\mathrm{D}_{\mathrm{G}}$

P36. O nome

tem origem grega, da qual derivam o nome de uma constelação e um signo zodiacal. Em uma versão de lenda da mitologia grega, Órion, o caçador, tentou violentar a deusa Artemis, que então mandou um para envenena-lo mortalmente. Agradecida ao Artemis o transformou em uma constelação. Fez o mesmo com Órion, e, como castigo, posicionou sua constelação em uma posição no céu em que fosse eternamente da constelação de mencionam a existência de diversas simbologias envolvendo o Marcussi et al. (2011) peçonhento. Esboçados os elementos culturais referentes ao " "traiçoeiro, sedutor, exótico e estamos nos referindo. Faça uma pesquisa para descobrir qual é este animal, bem como suas características biológicas e curiosidades. Faça um desenho/esquema da morfologia deste animal e explique. P37.

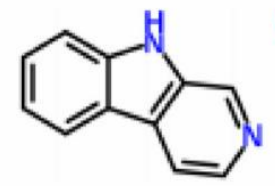<smiles>Cc1cc(=O)oc2cc(O)ccc12</smiles>

Essas substâncias apresentadas acima já foram detectadas na cutícula do escorpião (GAFFIN et al., 2012). Determine o nome dessas substâncias e explique qual a relação delas com a cutícula do escorpião. Que fenômeno está relacionado? Explique.

P38. Uma das hipóteses para a fluorescência do escorpião, recebendo radiação UV e emitindo luz visível, de cor verde-ciano brilhante (GAFFIN et al., 2012). O animal observaria essa luz visível e utilizaria a informação para avaliar a conveniência de sair para se alimentar ou, ao contrário, evitar o ambiente iluminado pela Lua (especialmente próximo à fase cheia e em seu zênite), situação em que ficaria vulnerável (KLOOCK el al., 2010).

Você sabe qual é a diferença entre fluorescência e fosforescência? Explique.

Faça uma pesquisa sobre como o fenômeno de fluorescência ocorre no escorpião e responda as seguintes questões:

O que ocorre se incidirmos radiação UV (luz negra) sobre um escorpião?

Qual a natureza da radiação incidente sobre o escorpião?

Que tipo de substância costuma provocar o fenômeno?

Fonte: Siqueira (2018) 